\title{
A Sociological analysis of life style changes and consumption patterns of Migrant Professionals at Doha
}

\author{
Dora Dominic \\ Assistant Professor, Department of Sociology, St. Teresa's College Ernakulam
}

\begin{abstract}
The study of migration occupies an important place in sociology as it deals with specific patterns and social problems associated with the migration. Changes in the physical location of an individual bring changes in the family ties. Disintegration of joint family and emergence of nuclear families permits social mobility easier breaking the knots and obligations of relations and social milieu. According to Hetcher (1966) one of the characteristic features of the development of industrial society is the separation of the individuals from the social roots and cultural cocoon that shaped him. He analyses that migration results internal and external changes at economic, political, religious social and cultural aspects. The present study focuses on the changes that migration made in the life style and consumption patterns of male migrant professionals from Kerala at Doha.
\end{abstract}

Key Words: Life style changes, Consumption pattern, Conspicuous Consumption, Migrants, professional

\section{Introduction}

A migration is defined as the movement of people from one defining area to the other. A migrant is a person who has changed his place of residence from one migration defining area to another at least once during the migration interval (AshaBhende and Tara Kanitkar ).Migration takes place at different levels that includes internal and external migration. Internal migration happens when people migrate from one region to the other. External migration occurs when people migrate from a country to other country. After the 1970s there has been an increase in the rate of international migration from India to other countries like USA, UK, Middle East and South Asian countries etc.

\begin{tabular}{l|llll|} 
Country & 2004 & \multicolumn{1}{c}{2005} & 2006 & 2007 \\
\hline U.A.E & 175262 & 194412 & 254774 & 312695 \\
Saudi Arabia & 123522 & 99879 & 134059 & 195437 \\
Oman & 33275 & 40931 & 67992 & 95462 \\
Qatar & 16325 & 50222 & 76324 & 88483 \\
\hline
\end{tabular}

Country wise Distribution of Annual Labour Outflows from India (2004-2007)

The oil boom in 1973 in the Middle East region motivated the Indian population to migrate for work to Gulf region. The social problems as poverty, unemployment, low wages and poor standard of living in the country made the Indians seek better opportunities. The international migration contributes to the development of the country and even the contributing country is benefited. Globalization has contributed to the development of World markets and IT revolution. The migration have its impact on family level as its contributing to family income, consumption patterns, better standard of living etc. From the developmental perspective of a country it has contributed to the improvement remittances, infrastructural development, increased GDP etc.

In India the southern state of Kerala received much attention in the 1970s in view of the large number of emigrants to gulf countries which resulted in a paradigm shift in the socio-economic conditions of certain regions in Kerala. It is worth noting that Kerala State alone received Rs. 18465 crores of remittances from gulf regions during 1999-2004. On an average, remittances from gulf country contribute 22 percent of state income.(Abdul Azeez and Mustiary Begum 2009).The study conducted by Zachariah et al. (2002) observes that migration from Kerala to other states of India and to countries abroad has become so rampant that its impact is felt in every aspect of life in the state.

At present almost all families in Kerala seem to have been affected by the Gulf migration in one way or other. Migration has affected every facet of life in Kerala economic, social, political and even religious. The push factors for the Gulf migration is the lack of employment opportunities, poverty, low standard of living, decline of agricultural economy, debts etc. Migration has been one of the positive outcomes of Kerala model of development. The states dynamic social development in the past half a century and relative stagnation in its productive sector have created ideal condition for an acceleration of migration from the state. Also the migrants have benefited from the current currency crisis. 


\section{Background of the Study}

Doha is Qatar's largest city with $60 \%$ of the nation's population. It has one of the largest per capita incomes in the world and its economy is primarily dependent on natural and oil gas reserves. The nation is currently undergoing tremendous changes and expects to achieve economic advancement in the coming years. In order to promote the tourism country has invested billions to improve the infrastructure. The economy and new industrial development expanded to clusters in Doha, Al Khor, Mesaieed and Dukan. The expatriate-nation proportion is 60:40 and statistics shows that 92.3\% of labor force in Qatar is emigrants. The largest portions of emigrants are from South Asian countries mainly India, Pakistan Philippines, Nepal and SriLanka. Indian community in Qatar is currently estimated at close to 500,000 unofficially. Indians are involved mostly in the construction sector mostly unskilled and unorganized sector and the rest of the Indians are professionals and business categories. And Qatar is one of the Gulf countries with large number of migrants from Kerala. The professionals in Qatar are mainly engineers, medical professionals, IT professionals, teachers, charted accountants, architect and others.

\section{Indian Professionals in Qatar}

In Qatar the prime demand comes from the oil gas industry and construction sector. The white collar professionals are the visible class in the Qatari society. They are dominant consumers in the shops, malls, public places etc. Most of the professionals are engineers, researchers, technical experts and the managerial staffs in companies. The Indians are also dominant in medical and health sectors - doctors, nurses and other staffs. The teachers and educational professionals are contributing to the educational sector. The others are the Charted Accountants, auditors, software professionals and the employers in the journalism and media-sector. Finally with the boom of construction sector there is dominant presence of engineers, architects, project managers and other real estate related supply groups.

\section{Life style Changes}

Lifestyle is the term that is given for a mode of living adopted by an individual or a group. Another facet was added when medicine started to conceive lifestyle as a way of healthy or unhealthy living, including nutrition, sports, media consumption and the general quality of life of individuals and collectives, including the respective social prerequisites. In another way it is a characteristic bundle of behaviors that makes sense to both others and oneself in a given time and place, including social relations, consumption, entertainment, and dress.Johannes Heinrichsstates that "lifestyles consist of the complex multidimensional interweaving of different dimensions and factors; they are often interpreted as the symbolic embodiment of culture in the broad sense, that is, to the extent that culture is defined as "the inheritable of social practice".

The migrants benefit economically from the gulf countries and they are not satisfied with items for basic sustenance but also they are eager to obtain a quality life of comfortable living. Even though the migrants are separated from home and friends the social networks are making them connected.

The changes in lifestyle can be seen mainly in the following areas

$\quad$ Food preferences
$\quad$ Clothing preferences
$\quad$ Enidence preferences
$\quad$ Particinment patterns
$\quad$ Affinity to electronic devices

The study attempts to find the mode of life adopted by the male professionals related with food preferences, affinity for electronic gadgets and branded clothing, western model of entertainment such as pubbing, partying, participation in social networks, preferred mode of residence, consumption of accessories etc. The access to global work culture and mixing up with different cultures of the world does make an impact on their social relations and preferences.

\section{Objectives}

- To study about the socio-economic background of the male migrant professionals from India at Doha

- To find out the life style changes of migrant male professionals from India. (Food preferences, Clothing preferences, residence preferences, entertainment patterns, participation in social networks, affinity to electronic devices)

- To analyze the goods consumption patterns of male professionals from India at Doha 


\section{Methodology}

In the present study descriptive analysis is used. The study is based on primary data and data was collected through snowball sampling.The tool used for collecting data was Questionnaire. The respondents were asked questions on the aspects as changes in the food habits, clothing preferences, residence preferences, entertainment patterns, participation in social networks, and affinity to electronic devices. The data was collected coded and analyzed using S.P.S.S

\section{Theoretical Framework}

Mostly Consumption pattern among migrants are getting converted to 'conspicuous consumption' and Veblen(1857-1929), states that that leisure itself is a costly is invisible and offers no particular status of advantage and finally it results unnecessary acquiring of luxury goods and services to publicly display economic power.

\section{Findings and Discussions}

The study was conducted to analyze the life style changes and consumption patterns of Migrant Professionals from Kerala at Doha.The study was conducted among the engineering professionals who are working in different companies at Doha. Most of the professionals in Qatar are paid between 5000-15000 QR. Of the respondents $58 \%$ were married and $42 \%$ were unmarried. $70 \%$ of the professionals are staying with their family and the companies are providing family status visa .Most of them are not living for long term in the country and all of them said that they have in Qatar for few years. The present boom and the peaceful life in Qatar have attracted large number of migrants to this region.

\section{Changes in the Food Preferences}

The migrants are having changes in the food habits as they have shifted from their home country. The presence of migrants has introduced foods from all over the world. Qatar's cuisine has been influenced by close links to Iran and India and more recently by the arrival of Arabs from North Africa and the Levant as well as Muslim dietary conventions. The Arabs generally refrain from eating pork and drinking alcohol, and neither is served publicly.

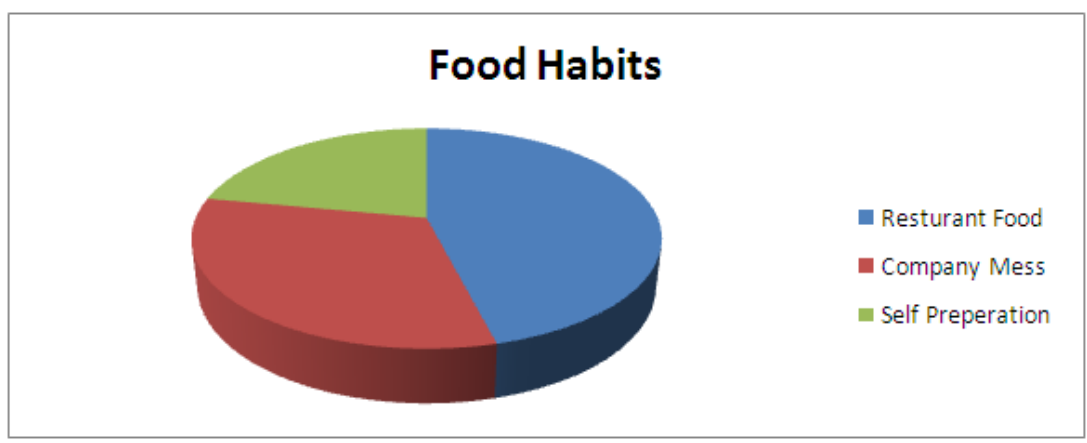

Due to the hectic work schedule most of the professionals rely on restaurant food and fast food. $46 \%$ of the professionals said that they are consuming food from restaurants $32 \%$ are preparing food of their own and others are consuming from the company mess. $50 \%$ of the respondents are interested in Indian cuisine and others prefer Chinese, Lebanese etc. The migration is having an impact on the food habits of the respondents.

\section{Changes in the Clothing Preferences}

Clothing is an important aspect of culture. $80 \%$ of the respondents said that they prefer branded clothes and $20 \%$ do not feel brand is necessary. The respondents said that while consuming goods $46 \%$ prioritize brand, $24 \%$ gives importance to the price, $22 \%$ gives importance to design of the clothes and $8 \%$ prioritize quality of the products.

\section{Changes in Residence Preferences}

Doha is now a more expensive city than Dubai in terms of real estate prices. The cost of living in Doha/Qatar is considered high compared to other places. The overall cost of living is determined using the prices for defined quantities of the same goods and services across 10 Expense Groups. In 2012, Doha is ranked 194 overall out of 950 cities globally .Accommodation costs such as house/flat rental, household utilities, local property rates and mortgage etc and are very high compared to other places. Currently Doha is ranked 50 in this expense group.The migrants are not provided permanent residence in the country. 54\% of the respondents prefer 
to live in the company accommodation itself as the house rent is very expensive. A single room flat cost 2500$3000 \mathrm{qr}$ a month and that is expensive when compared with other gulf countries.28\% prefer to live in rented flat as it gives more privacy. And $18 \%$ prefer to live in own flat.

\section{Affinity towards Electronic Devices}

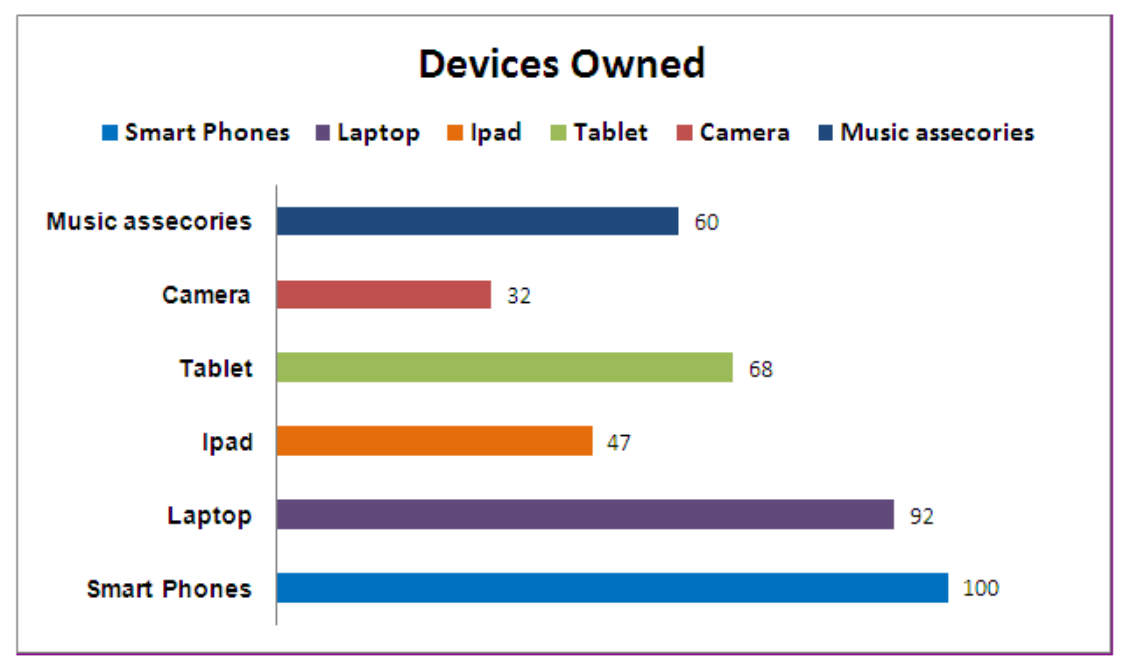

From the bar chart it is evident that $60 \%$ are using music accessories as mp3 player, music system and so on. Only $32 \%$ are using digital as well as DSLR cameras. $68 \%$ are using Tablet and $47 \%$ are using I pad and they are using these devices for job related purpose and personal use. The most used devices are Laptop's and Smartphones.

Smart phones are used for a variety of purposes, including keeping in touch with family members, conducting business, and having access to a telephone in the event of an emergency. Some people carry more than one cell phone for different purposes, such as for business and personal use. Multiple SIM cards may also be used to take advantage of the benefits of different calling plans - a particular plan might provide cheaper local calls, long-distance calls, international calls, or roaming. They are also using social network sites through mobile phones. This is an important aspect in the life of migrants

\section{Participation in Social Networking}

The professional's uses smartphones provided by the employer and they use bbm messages and emailing in mobile phones. The respondents said that they cannot avoid smart phones as their personal apps and social networks help them to connect to the outside world.All the respondents have their own personal laptop and they use viop calls and skype to communicate to the family and friends. The most popular social networking is face book and $92 \%$ of the respondents are spending hours in the social networks. The respondents are using then during work hours. Majority said that they carryout personal tasks as checking face book, conduct chats, mailing etc during work hours and also they are doing it as leisure activity after the work too.

\section{Mode of Entertainment}

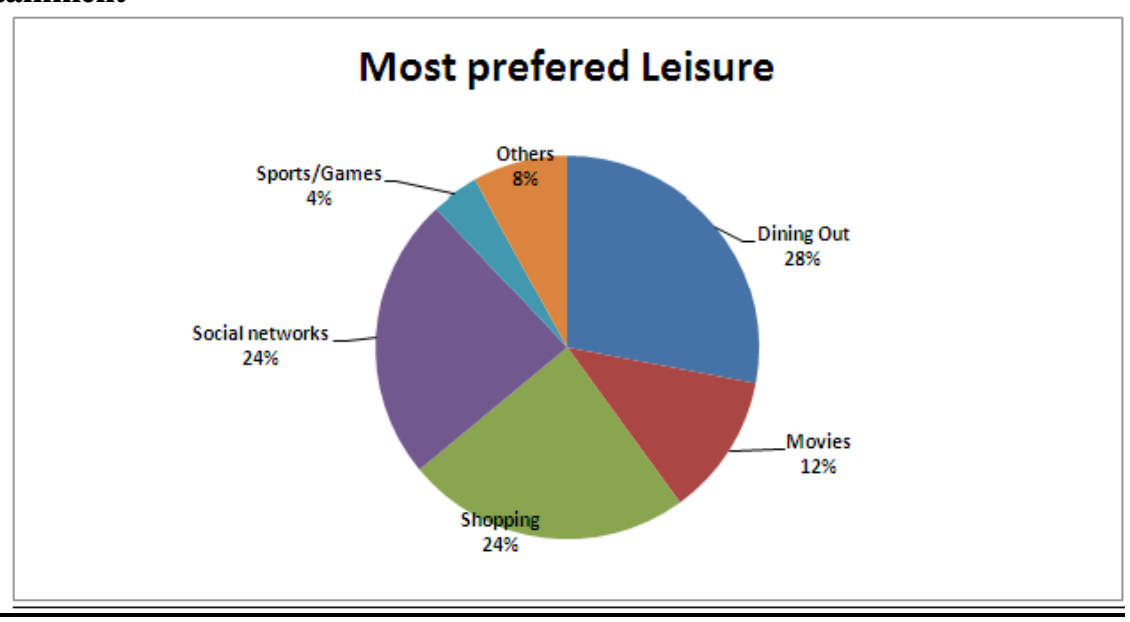


From the above diagram it is evident that the respondents are most interested in dining out, Shopping and using Social Networks. Some are interested in watching movies and very few are involved in sports and games and others are involved in activities as travelling, partying and so on.

\section{Extend of Change}

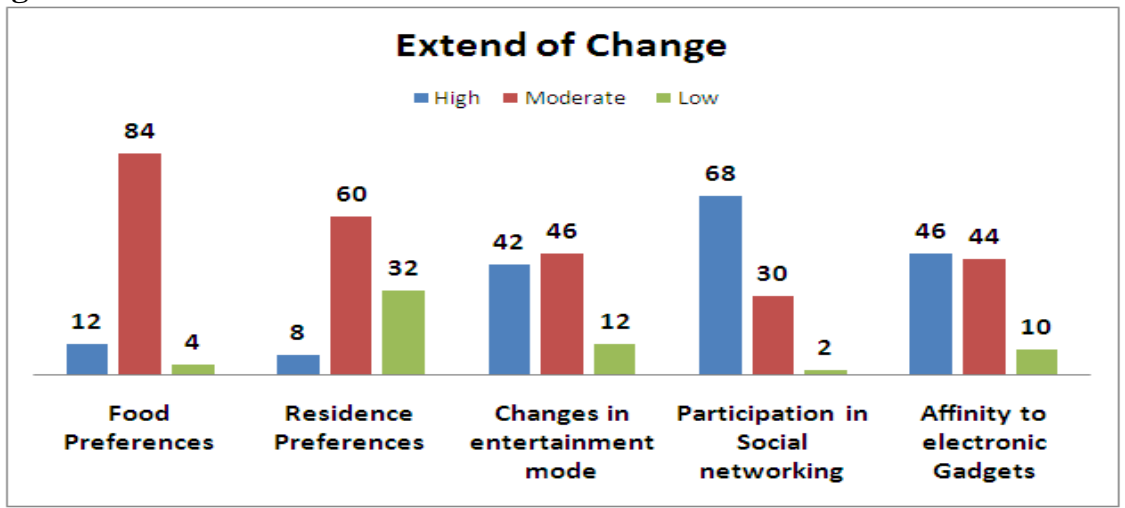

\section{Goods Consumption Patterns}

\section{Items for which respondents are spending the money most}

From the diagram it is evident that $48 \%$ of the respondents are spending money for clothes $24 \%$ are spending money for good food $16 \%$ for fashion accessories, $8 \%$ for electronic gadgets and $4 \%$ for other aspects. The respondents said that while consuming goods $46 \%$ prioritize brand, $24 \%$ gives importance to the price, $22 \%$ gives importance to design of the clothes and $8 \%$ prioritize quality of the products. From this it is evident that the professionals are brand conscious and they are spending money to get the best product.

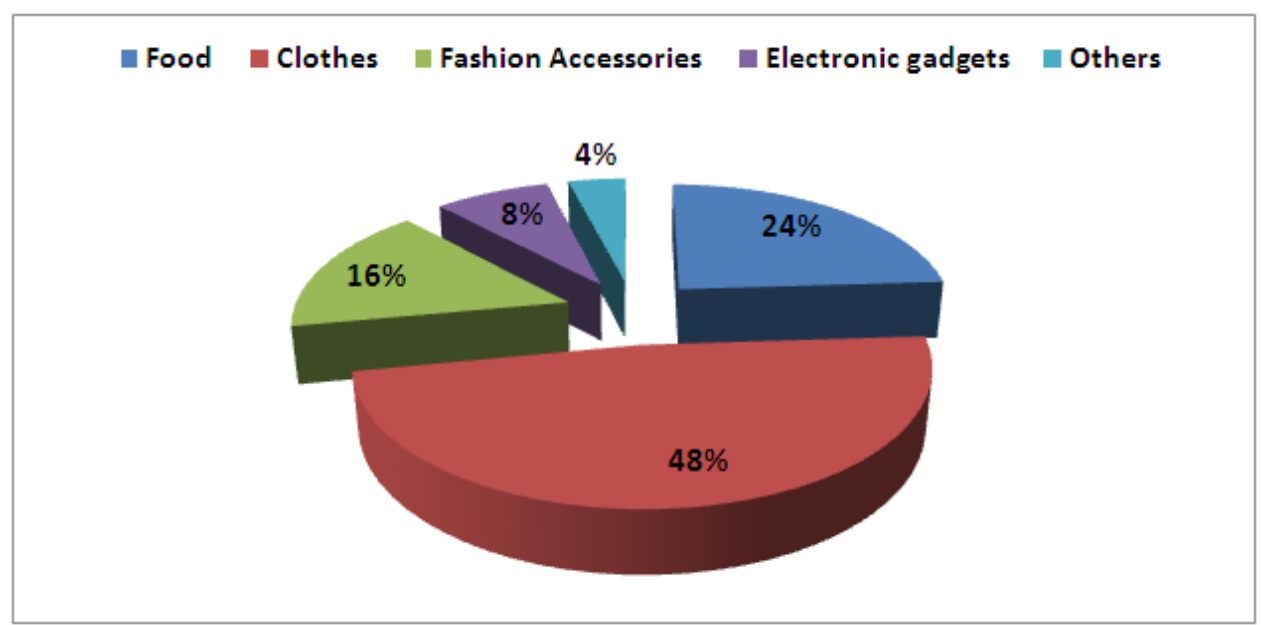

\section{Reasons for consuming branded and expensivegoods}

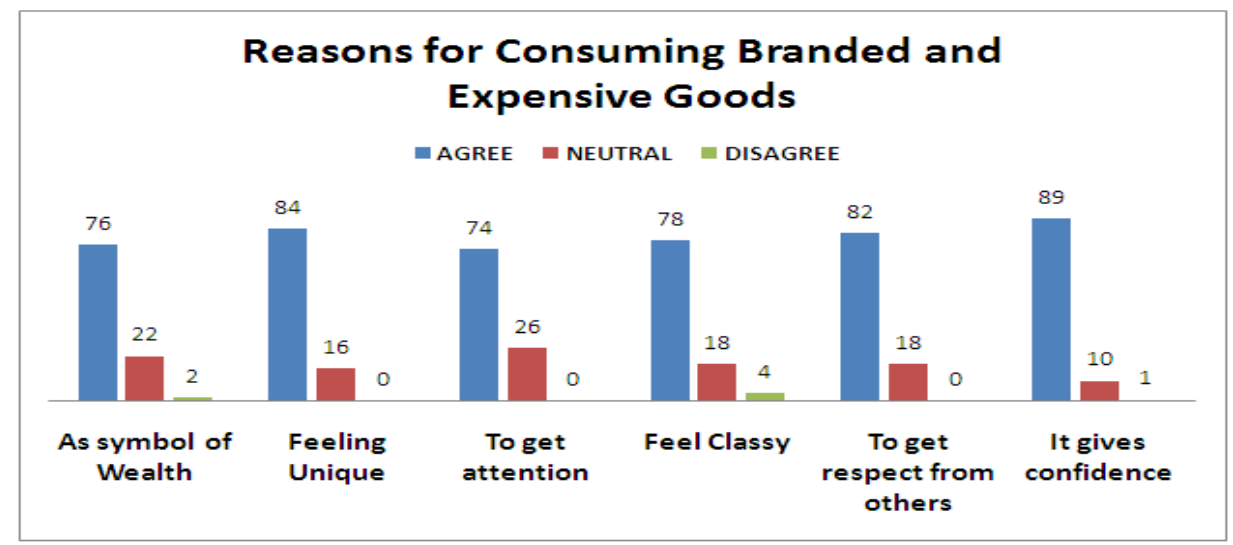


From the chart it is evident that most of the respondents are consuming the branded and expensive goods as the status symbol and also to get attention and appreciation from the others. Also they are gaining confidence and sense of uniqueness in consuming the brands.

\section{Conclusion}

To conclude, the emigration to gulf countries has changed the life style of the migrants. Consumption patterns have an important role in depicting the social status of the consumers. Among the migrants professionals are having better payment and social status. The people are using branded products to get social acceptance and appreciation. To gain this conspicuous consumption is prevalent among the professionals. Also they have different feelings associated with the consumption patterns. It is evident that the migration has changed the food habits, residence preferences, entertainment patterns etc.

\section{Reference}

[1]. Bende, Asha A. and Tara Kanitkar (2003), Principles of Population Studies, Sixteenth Revised Edition,. Mumbai: Himalaya Publishing House

[2]. Clark, A.E. and Oswald, A.J. (1996), 'Satisfaction and comparison income', Journal of Public Economics, 61, pp. 359-381

[3]. Cushing-Daniels, B. (2004), 'Migration in the US: What Role Welfare?, Gettysburg College, PA,

[4]. Dupor, B. and Wen-Fang, Liu (2003), 'Jealousy and equilibrium overconsumption', American Economic Review, 93(1), pp. 423-428

[5]. Ferrer-i-Carbonel, A. and Frijters, P. (2004), 'The effect of metholodogy on the determinants of happiness', Economic Journal, 114, pp. 641-659

[6]. Frank, Robert H. (1985), 'The Demand for unobservable and other positional goods', American Economic Review, 71(1), pp. 101-116 